\title{
Recognition of and steps to mitigate anxiety and fear of pain in injectable diabetes treatment
}

This article was published in the following Dove Press journal:

Diabetes, Metabolic Syndrome and Obesity:Targets and Therapy

16 January 2015

Number of times this article has been viewed

\section{Davida F Kruger' \\ Susan LaRue ${ }^{2,3}$ \\ Phil Estepa ${ }^{3}$}

'Henry Ford Health System, Detroit, MI, USA; ${ }^{2}$ Amylin Pharmaceuticals, San Diego, CA, USA ${ }^{3}$ AstraZeneca, San Diego, CA, USA
Correspondence: Davida F Kruger Henry Ford Health System, Division of Endocrinology, Diabetes, Bone and Mineral Disease, New Center One, 303I West Grand Blvd, Suite 800 ,

Detroit, MI 48202, USA

$\mathrm{Tel}+\mathrm{I} 3139163906$

Fax +I 3139163907

Email dkrugerl@hfhs.org

\begin{abstract}
Injectable treatments, such as glucagon-like peptide-1 receptor agonists and insulin, are options for the pharmacologic treatment of type 2 diabetes. Numerous barriers lead to delay in initiating injectable treatment, which, in turn, may lead to inadequate glycemic control and increased risk of diabetes-related complications, underscoring the need to understand and address these barriers. Barriers to the initiation of injectable therapy, strategies to mitigate barriers, and information about needle attributes and their relation to needle pain are reviewed on the basis of published literature retrieval and our clinical experience. Barriers to the initiation of injectable therapy originate from both patients and practitioners. Anxiety about and fear of injection-associated pain has been estimated to affect approximately $30 \%-50 \%$ of patients before the initiation of diabetes education interventions. Advances in needle design have minimized the pain associated with injections, and recent data suggest that actual pain and bleeding associated with various needle gauges (21-gauge to 31-gauge) are mild. Other barriers include concerns about the ability to handle injectable therapy, concerns about treatment side effects, and impacts on quality of life. Practitioners can help to mitigate barriers to injectable treatment for type 2 diabetes by understanding patient perceptions, improving education, and setting realistic expectations about therapy. Strategies for minimizing injection-associated fear and anxiety include a combination of assessment, appropriate needle selection, patient education, behavioral interventions, and monitoring.
\end{abstract}

Keywords: type 2 diabetes, injection, needle, anxiety, fear

\section{Introduction}

Type 2 diabetes (T2D) is a chronic disease characterized by insulin resistance and elevated blood glucose, compensatory hyperinsulinemia, and progressive pancreatic $\beta$-cell destruction. ${ }^{1}$ The pathophysiology of T2D involves multiple organs and tissues, including pancreatic $\alpha$ and $\beta$ cells, muscle, liver, adipose tissue, the small intestine, the kidney, and the brain. Effective treatment requires the use of agents that target the multiple pathogenic abnormalities of T2D, and treatment should be initiated early in the natural history of the disease to prevent progressive $\beta$-cell failure. ${ }^{1}$ Uncontrolled blood glucose over time significantly increases the risk of mortality and diabetes-related morbidity, necessitating early management. ${ }^{2}$

Current treatment guidelines recommend metformin as first-line therapy for the early management of T2D, except in patients with a contraindication. ${ }^{3-5}$ Patients who have high baseline glycated hemoglobin (A1C) (eg, $\geq 9.0 \%$ ) may have a low probability of achieving target A1C with monotherapy and may benefit from first-line combination therapy. ${ }^{3-5}$ However, in patients who receive initial treatment with monotherapy, 
maintenance of individualized glycemic targets over the long term is unlikely due to the progressive nature of the disease. Approximately $55 \%-70 \%$ of patients who achieve glycemic targets with initial monotherapy will fail to maintain these targets 2-3 years later. ${ }^{6}$ Thus, when monotherapy alone fails to achieve or maintain target $\mathrm{A} 1 \mathrm{C}$, the addition of a second oral agent or injectable treatment such as a glucagon-like peptide-1 receptor agonist (GLP-1RA) or basal insulin is recommended. Guidelines also stress the importance of a patient-centered approach with regard to treatment choice and sequence of therapy. ${ }^{3-5}$

Many patients express reluctance to begin injectable therapy, leading to delayed initiation and low persistence with treatment. ${ }^{7,8}$ Multiple studies have identified both provider-related and patient-related barriers to the initiation of insulin, ${ }^{9-13}$ which may translate into resistance to other injectable therapies for diabetes. Herein, we discuss potential barriers to the initiation of injectable therapy in patients with T2D, including steps that can be taken to mitigate anxiety and fear, and how to improve patient acceptance and adherence.

\section{Review criteria}

The articles in this review were identified by a literature search in PubMed for articles published in the last 15 years using the keywords "shorter needle," "needle pain," "injection pain," "needle anxiety," "needle fear," "injection fear," "diabetes," and "psychological insulin resistance." Papers were included on the basis of a manual selection from the search results based on the clinical relevance to the topic. When evidence from primary studies was lacking, review articles and additional relevant articles from the authors' database and the references cited in selected papers were also included.

\section{Factors influencing the initiation of injectable therapies in T2D}

Numerous factors act as barriers to the initiation of injectable therapy and may originate with either the practitioner or the patient. Practitioners may have a negative baseline assumption that the average patient with diabetes may not be capable of handling insulin. ${ }^{14}$ In two separate surveys of primary care providers, a majority ( $64 \%$ and $92 \%$ ) indicated a belief that their patients would fail to comply with or adhere to insulin therapy, and $28 \%$ and $47 \%$ believed that their patients would be unable to accept the discomfort and pain from injections. ${ }^{9,12}$ An additional barrier is the negative connotation associated with insulin therapy that may be mistakenly associated with other injectable therapies such as GLP-1RA. ${ }^{9}$ For example, both practitioners and patients have very real concerns about the side effects of hypoglycemia and weight gain associated with insulin, but these side effects are not concerns for a GLP-1RA.

Also, some patients view the initiation of injectable therapy as a failure on their part to control their disease, rather than understanding the progressive nature of T2D. Contributing to this barrier is that practitioners struggle with a shortage of resources to properly educate patients about their disease ${ }^{15}$ and may preferentially choose oral glucoselowering medications over injectable therapies for matters of convenience. Although this initial therapeutic decision may be to the patient's liking, it sets up a scenario of failure and self-blame when, despite the patient's best efforts, long-term glycemic control is not maintained and injectable therapy is required. ${ }^{10}$ The practice of reserving insulin or injectable therapy as an option of last resort also allows clinicians to use injectable therapy as a threat ${ }^{10,13,16}$ and may perpetuate the overall anxieties and fears that patients have about being able to handle injectable therapies and manage injectionassociated pain. In addition, patients with T2D are approximately two times more likely than patients without diabetes to have major depression, with an estimated prevalence of $20 \%-30 \%,{ }^{17,18}$ and depression has been associated with poor glycemic control $(P<0.0001)$, negative perceptions of insulin therapy $(P=0.02)$, and poor adherence $(P<0.0001) .{ }^{19-21}$ Thus, before initiating injectable therapy, practitioners should consider evaluating for and addressing underlying depression or other psychological problems in their patients, including anxieties and fears that may increase patient resistance to therapy.

Negative perceptions of injectable therapy from patients may stem from familiarity with family members or friends with T2D who were receiving injectable therapies and went on to experience complications or even death. ${ }^{16}$ These experiences, which are possible, but not the same, for every patient, may negatively impact the perceptions of new patients toward their disease state and injectable therapies. Patients also may have negative perceptions of insulin therapy that may be translatable to other injectable therapy. In a survey of insulinnaïve patients with diabetes, negative attitudes toward insulin were common. Indeed, $28 \%$ of patients indicated that they were unwilling to initiate insulin therapy if prescribed. Significantly more patients unwilling to initiate insulin therapy than willing patients agreed with negative beliefs about insulin, including low self-efficacy (ie, not confident they could handle the injections), restrictiveness on life, personal 
failure in taking care of their diabetes, insulin performance (ie, belief that once insulin therapy is started, it cannot be discontinued), anticipated needle pain, problematic hypoglycemia, increase in illness severity, lack of fairness, and expected harm such as blindness ( $P \leq 0.02$ for all). ${ }^{11}$ Another survey of insulin-naïve nonadherent patients who failed to initiate newly prescribed insulin therapy versus adherent patients who did initiate insulin therapy yielded similar negative sentiments about insulin therapy. ${ }^{22}$ The most common reasons nonadherent patients failed to initiate insulin therapy were related to plans to change health behaviors, injection phobia, pain, negative impact on social life or work, concerns about long-term medication use, inconvenience, belief that insulin was not needed, and harms from insulin (eg, blindness, renal failure, amputations, heart attacks, strokes, and early death). ${ }^{22}$

Fear of injectable therapy is a main concern for many patients. In a survey of insulin-naïve patients with T2D, $34.7 \%$ of patients anticipated pain with insulin therapy, and this proportion was greater in patients unwilling to initiate insulin (50.8\% versus $30.2 \%$ of willing patients). ${ }^{11}$ Moreover, in a survey of insulin-naïve patients recently prescribed insulin therapy, $13 \%$ cited injection phobia as a reason for not initiating insulin therapy, and $30 \%$ of nonadherent patients believed injections would be painful, compared with $15 \%$ of adherent patients. ${ }^{22}$ In a study of needle fear in pregnant women with pregestational and gestational diabetes, $43 \%$ exhibited fear of needles at baseline; however, a multifaceted diabetes education program, including instruction on self-injections and self-monitoring, was successful in reducing injection fear $(P=0.001)$ and fear of self-testing $(P=0.012) .{ }^{23}$ Injection-related fear is associated with poor glycemic control, increased risk of mortality, and other comorbidities. ${ }^{24}$ Thus, the prompt mitigation of anxiety about and fear of pain, and, if possible, the actual pain itself, is of great importance to the success of diabetes therapy.

\section{Factors influencing injection pain}

Because the fear of injection-related pain is a real barrier to successful initiation of injectable therapy, this section describes how various needle attributes may influence injection pain, including length, gauge (diameter), bevel design, and other enhancements that reduce needle wall size (microtapering). Injection-related pain, bleeding, and bruising in diabetes therapy is relatively common. In a survey of 501 patients with diabetes who used a syringe or pen device to deliver insulin, almost half reported injection-related bruising, and $37 \%$ reported injection-related pain. ${ }^{8}$
It is widely assumed that increased needle length is likely to be associated with increased injection pain, and although there are data that support this view, ${ }^{25}$ not all studies are confirmatory. ${ }^{26,27}$ An open-label crossover study of obese patients with T2D assessed pain associated with both short $(5 \mathrm{~mm})$ and long $(8 \mathrm{~mm})$ needles of the same gauge using a visual analog scale (VAS). ${ }^{27}$ The VAS is a linear scale used to assess pain encompassing a range of numbers $(0-10$ or $0-100)$, such that the lowest number is indicative of no pain and the highest number is indicative of the worst pain possible. Both needles were associated with low mean VAS scores for pain overall (a rating of 7 [5 mm needle] versus a rating of 9 [8 mm needle] out of 100), and differences between the needles were not significant (Figure 1). ${ }^{27}$

Although patients may be mostly concerned with the length of the needle, needle gauge also may influence possible injection-associated pain. ${ }^{25}$ In a study using automated needle insertions of varying gauge (23-32 gauge) into the abdomen and thigh, investigators evaluated the number of painful insertions in patients and collected VAS data to further measure differences in pain. Needles with lower gauges were significantly associated with a greater quantity of painful insertions compared with higher-gauge needles

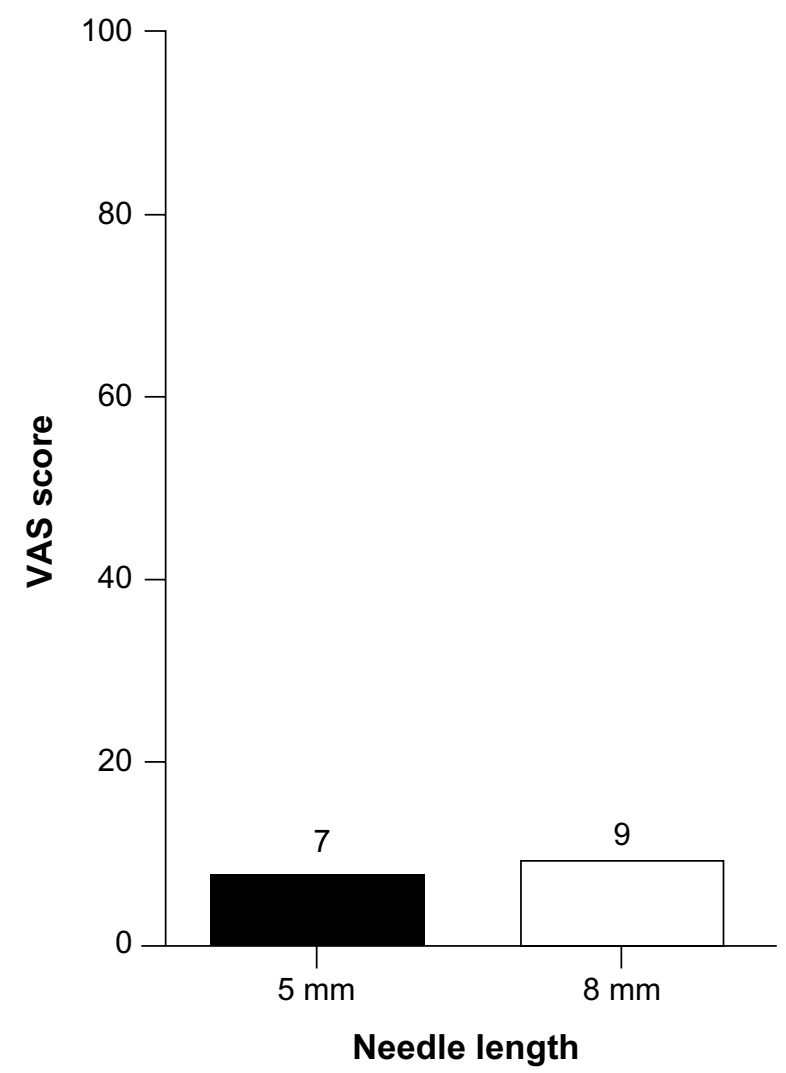

Figure I VAS pain scores for $5 \mathrm{~mm}$ and $8 \mathrm{~mm}$ needles. Abbreviation: VAS, visual analog scale. 
$(P<0.0001)$; however, no significant trends were observed between needles when looking at VAS scores for pain. ${ }^{28}$ This raises the question of whether the sensation of needle insertion, which may be heightened with the use of a wider needle diameter, may be mistakenly identified as pain. In a separate study of 62 obese patients with T2D assessed with the Insulin Treatment Satisfaction Questionnaire, use of a 29-gauge, $12.7 \mathrm{~mm}$ needle compared with a 31-gauge, $6 \mathrm{~mm}$ needle was associated with no significant difference in pain, though a large majority of patients preferred using the shorter, thinner needle ( $89 \%$ versus $11 \% ; P<0.001){ }^{29}$

In a nondrug, multicenter, randomized, open-label study of 67 patients with a mean duration of diabetes of approximately 9 years and a mean history of injecting insulin of approximately 4 years, the preference for injections with needles of varying gauge (21-gauge, 23-gauge, 25 -gauge [6 mm], tapered 27-gauge [8 mm], and 31-gauge [5/16 inch, $\sim 6 \mathrm{~mm}]$ ) was compared (data on file). Patients performed four pairs of normal saline injections in a randomized sequence at two visits approximately 7 days ( \pm 3 days) apart. The mean injection pain intensity for each needle gauge was rated "faint" to "very mild" on the Gracely Box Scale, a validated scale that is similar to the VAS but incorporates words matched to the numbers to detect smaller differences in pain at the lower end of the scale. ${ }^{30}$ Although patients generally expressed a preference for the thinnergauge needles, minimal difference was observed in the pain ratings among the 21-gauge, 23-gauge, 25-gauge, and 31 -gauge needles, with the 23-gauge and 25-gauge needles falling below the "very weak" rating and the 31-gauge needle below the "faint" rating (Figure 2). Bleeding for all needles evaluated in the study were within the "no blood" to "mild" rating (scale score: $0=$ no observable blood/injectate, $1=$ mild $[\geq 0.02 \mathrm{~mm}$ and $<1.5 \mathrm{~mm}], 2=$ moderate $[\geq 1.5 \mathrm{~mm}$ and $<4 \mathrm{~mm}$ ], $3=$ severe [ $\geq 4 \mathrm{~mm}]$ ), with minimal difference observed among the 21-gauge, 23-gauge, 25-gauge, and 31-gauge needles (Figure 3). No serious adverse events were reported. Data from this study raise the question of whether needles with lower gauges are unnecessarily perceived as more painful, because patient-rated pain intensity for all needle gauges was only faint to mild.

Thin-wall needle design, or microtapering, is a feature of needles that allows for a larger internal diameter but a narrower outer diameter. The evidence of pain reduction with microtapered needles is conflicting. In a nonrandomized, single-arm study, 97 patients with diabetes were evaluated for 2 weeks each for their preference of a 31-gauge thin-wall or normal-wall needle. ${ }^{31}$ At the end of the study, a greater proportion of patients preferred the needle with the thinwall design compared with the needle with the normal wall (78\% versus $8 \% ; P<0.001$ ), and significantly more patients experienced less pain, bleeding, and skin irritation using the thin-wall needle $(P<0.001)$. However, in a separate open-label, randomized crossover study of 84 patients, a 32-gauge $4 \mathrm{~mm}$ straight needle was associated with less pain compared with a 33-gauge, $5 \mathrm{~mm}$ microtapered needle (mean change, $-14.5 \mathrm{~mm} ; 95 \%$ confidence interval, $-20.9 \mathrm{~mm}$ to $-8.0 \mathrm{~mm})$ and was more highly preferred $(60.3 \%$ versus $19.2 \% ; P<0.0001),{ }^{32}$ pointing to the importance of needle size over microtapering to patients.

A final needle attribute that may impact perceived pain is the bevel of the needle. Different bevel designs, including modifications to the angle or length of the bevel, can enhance sharpness, a factor that impacts the ease of needle

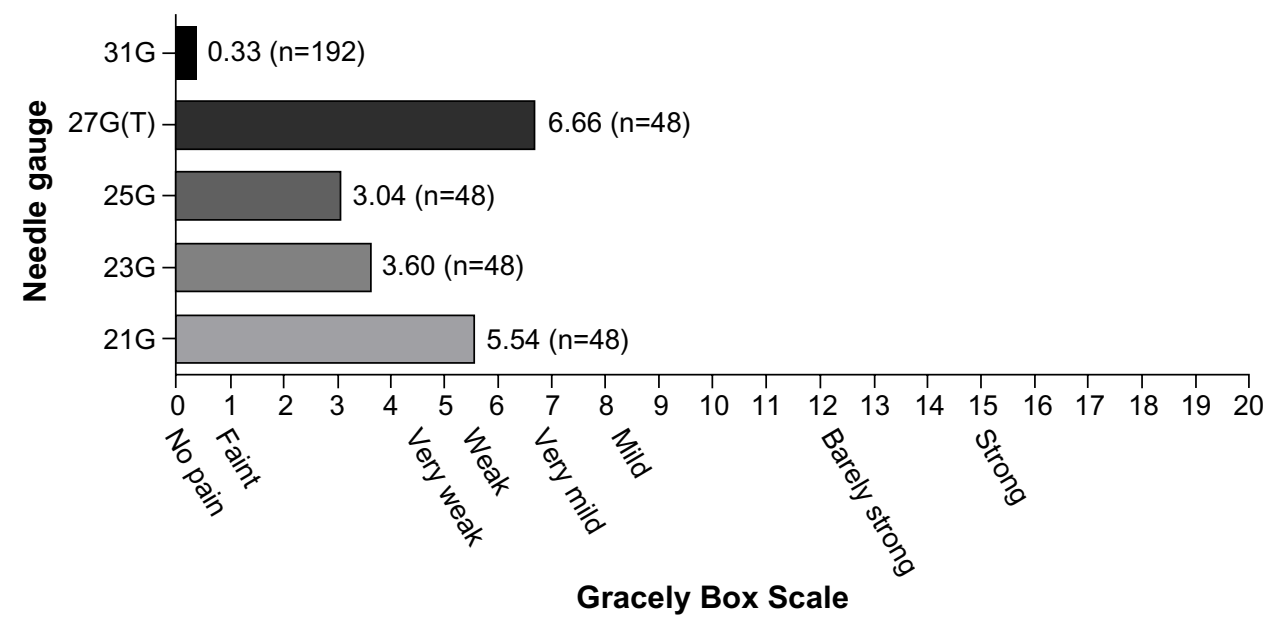

Figure 2 Mean injection site pain intensity (data on file). Abbreviations: G, gauge; $T$, tapered. 


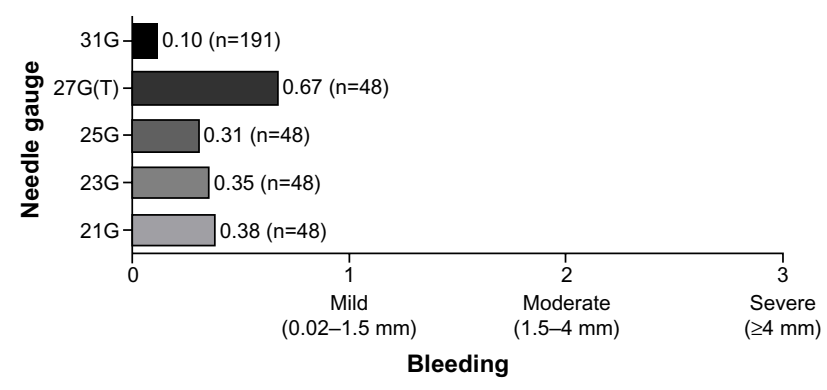

Figure 3 Mean injection site bruising or bleeding (data on file). Abbreviations: $\mathrm{G}$, gauge; $\mathrm{T}$, tapered.

insertion..$^{25,33}$ During laboratory penetration force testing, 5 -bevel needles were associated with a $23 \%$ decreased mean penetration force into a skin substitute model, compared with 3-bevel needles $(P \leq 0.01) .{ }^{34}$ When tested by insulin-taking patients in the home setting where they were informed that they were testing a new needle design compared to their usual 3-bevel pen needle, significantly more patients favored the 5-bevel needles compared with 3-bevel needles for comfort $(61.9 \%$ versus $8.3 \%)$, ease of insertion $(63.1 \%$ versus $7.1 \%$ ), and preference (60.7\% versus $10.7 \%$ ) (all $P<0.01$ ); however, no significant differences were observed between bevel designs when testing was blinded.

Although recent enhancements in needle design, such as microtapering and bevel changes, have helped to address some issues of patient discomfort, fear and negative perceptions of injectable therapy remain. With sensitivity to and awareness of these fears, practitioners can take proactive steps to help patients overcome the fear of and anxiety about injection-associated pain.

\section{Strategies for overcoming perceived injection-associated pain}

$\mathrm{T} 2 \mathrm{D}$ is a lifelong condition and the prospect of having to self-inject diabetes medication on a long-term basis could potentially be challenging for individuals. Mitigating fears of injection-associated pain and increasing patient acceptance of injectable therapy and glucose self-monitoring require a combination of assessment, appropriate selection of needles, education, behavioral interventions, and monitoring (Table 1).

Before initiating injectable therapy, clinicians should assess each patient's level of injection fear. The Diabetes Fear of Injecting and Self-testing Questionnaire is one tool to help clinicians identify patients who may exhibit avoidance behaviors that are detrimental to their care. ${ }^{35}$ Rather than using standardized surveys, clinicians may also prefer to ask openended questions (Table 2) or use the importance-confidence
Table I Strategies for overcoming injection-associated pain

\begin{tabular}{ll}
\hline Category & Strategy \\
\hline $\begin{array}{ll}\text { Assessment } & \text { - Identify past experiences with injections } \\
\text { of fear } & \text { - Identify perceptions about injectable therapy } \\
& \circ \text { Ask open-ended questions } \\
\text { Needle selection } & \text { - Use standardized surveys (D-FISQ; Nagai et a }{ }^{32} \text { ) } \\
& \text { are smaller and thinner or that improve the ease } \\
& \text { of insertion } \\
\text { Patient education } & \text { - Show patients the needles that they will be using } \\
& \text { for insulin injections and diabetes self-monitoring } \\
& \text { - Discuss how needles have been designed } \\
& \text { to improve patient comfort } \\
\text { Behavioral } & \text { - Instruct on proper injection technique } \\
\text { interventions } & \text { Allow for supervised injection rehearsals } \\
\text { Monitoring of } & \text { Deep breathing } \\
\text { therapy } & \text { Forceful exhale during injection } \\
& \text { Assess patient response to prescribed injectable } \\
& \text { therapies } \\
& \text { - Inform about and offer alternative regimens to } \\
& \text { maintain adherence and minimize pain } \\
& \text { Provide follow-up education and counseling as } \\
& \text { needed }\end{array}$ \\
\hline
\end{tabular}

Abbreviation: D-FISQ, Diabetes Fear of Injecting and Self-testing Questionnaire.

ruler, a tool used in motivational interviewing techniques, to assess patient concerns. ${ }^{36,37}$ The fear of many patients regarding self-injection and self-monitoring may stem from previous experiences with needles in their medical history; therefore, assessment of medical history should be included in the initial assessment. ${ }^{16}$

As stated earlier, patients generally indicate a preference for smaller, thinner needles even though the actual pain caused by smaller, thinner needles compared with larger, thicker needles is not significantly different (as measured by VAS). ${ }^{29,32}$ The selection of short, thin needles $(\leq 6 \mathrm{~mm})$ can help to mitigate the anxiety and fear of injections. In a study of 30 patients with diabetes using both a 32-gauge,

Table 2 Open-ended questions to assess patient barriers to injectable therapy

- How satisfied are you with your current diabetes therapy?

- How do you think injectable therapy can help with your diabetes?

- Who do you know who has taken injectable therapy and what was their experience?

- What is your past experience with taking injectable medications?

- What is your greatest concern about starting injectable therapy?

- How confident are you that you can take injectable therapy on a regular basis?

- What obstacles do you think will keep you from taking injectable therapy?

- What information/support do you need to have to be willing to take injectable therapy? 
$6 \mathrm{~mm}$ tapered needle tip and a 31-gauge, $5 \mathrm{~mm}$ standard needle tip for 1 week each, patients expressed that they were less frightened and less fearful of pain upon needle insertion $(P<0.05)$ and experienced less pain $(P<0.01)$ and less bruising $(P<0.001)$ using the $6 \mathrm{~mm}$ needle tip compared with the $5 \mathrm{~mm}$ needle tip. ${ }^{38}$ Practitioners can educate patients that needles used for injectable antidiabetes therapies and selftesting (ie, subcutaneous injections) are smaller and thinner than needles used for vaccinations or other depot medications (ie, intramuscular injections) that they may have received. A simple visual demonstration of different needle sizes during an office visit may be useful to reinforce this message. Patients may also find it helpful to have a trial injection that is supervised in the office setting. ${ }^{16,39}$ Allowing the patient to conduct a trial injection during an office visit with or without medication and with or without assistance from a member of the health care team may help to assuage fears as well as ensure that injection technique is correct. For patients who are particularly apprehensive about and fearful of pain, the use of a pen-injector that hides the needle from view may be beneficial. ${ }^{36}$

Research into injection techniques that minimize pain is limited, but there are general recommendations that may help and that should be clearly communicated to patients. ${ }^{40}$ Before injection, patients should allow sufficient time for any alcohol from the use of prep wipes to evaporate from the skin. ${ }^{41}$ Leftover alcohol may cause local irritation during needle insertion. Patients also should be discouraged from wiping needles with alcohol, as factory coatings that ease skin penetration may be accidentally removed, resulting in more painful injections. At the chosen injection site and with the underlying muscles relaxed, the needle should be inserted under the skin quickly, with the same needle position maintained until the injection is completed and the needle is withdrawn. ${ }^{40,41}$ Whereas using an angled injection has not been proven to reduce injection-associated pain, it has been shown to help reduce accidental intramuscular injections that could affect absorption. ${ }^{42}$ If an injection is painful or begins seeping after it is completed, finger pressure at the injection site for at least 5 seconds, without rubbing, may be helpful. ${ }^{41}$

Distractions with or without verbal suggestion, breathing methods, hypnosis, and combined cognitive-behavioral techniques have shown some efficacy (albeit limited and not always statistically significant) in children and adolescents for the reduction of injection-associated pain and anxiety. ${ }^{43-45}$ The applicability of these techniques in adults is less certain, owing to a lack of firm research. One technique that may be easily adopted in adult patients who are self-injecting medications includes breathing techniques, such as taking deep breaths before the injection and exhaling forcefully during the injection.

Finally, monitoring of the patient after initiation of injectable therapy is essential to ensure that prescribed injectable therapies are tolerable. ${ }^{40}$ If regimens are not tolerable, patient adherence will become an issue. At least one study has demonstrated that patients are willing to forego treatment benefits to reduce the number of daily insulin injections, ${ }^{46}$ and multiple other studies have demonstrated that less frequent daily dosing is preferred and may improve likely adherence to treatment with oral antihyperglycemic agents in patients with $\mathrm{T} 2 \mathrm{D}^{47}$ or with other chronic conditions..$^{48-50}$ In a recent patient preference study of 184 patients with T2D, Hauber et al ${ }^{51}$ conducted a discrete-choice experiment in injection-naïve patients and found that patients would choose once-weekly injectable treatment over daily injections even if less-desirable injection features (eg, longer, thicker needles, weak pain sensation, or presence of nodules) were associated with the choice of less-frequent dosing. Through monitoring, clinicians can be aware of tolerability issues and can offer additional alternatives or regimens that may afford more comfort or, as a last resort, can consider referral to a psychologist for intervention. ${ }^{36}$ Finally, monitoring is also important to ensure that correct injection technique is being consistently practiced by patients. ${ }^{40}$ At subsequent clinic visits after the initiation of injectable therapy, patients can be reassessed for their injection technique, with education and correction provided by a member of the health care team as needed.

\section{Conclusion}

Because of the progressive nature of T2D, injectable treatment with either a GLP-1RA or insulin will be required for most patients. Despite advances in needle design that have greatly minimized pain, anxiety and fear about injection and needle use are common and are major contributors to nonadherence. Although patients generally indicate a greater preference for and decreased anxiety about the use of needles that are of shorter length and of higher gauge, this does not necessarily mean that needles that are longer and of lower gauge are more painful. Data from a nondrug, multicenter, randomized, open-label study indicate that lower-gauge needles (23-gauge and 25-gauge) were rated below the very weak rating on a pain-intensity scale and below the mild rating for injection-site bleeding. 
Nonadherence to injectable therapy may result in inadequate glycemic control and increased risk of diabetesrelated complications and mortality. Practitioners can help to mitigate barriers to injectable therapy by understanding patient perceptions, improving education, and setting realistic expectations about therapy. Tools and strategies that may help facilitate improved initiation of and acceptance to injectable therapy in patients with type 2 diabetes include the comprehensive assessment of patient fears, appropriate needle selection, patient education, the use of behavioral interventions such as breathing exercises, and follow-up monitoring. More research is needed to assess and validate the benefits of different behavioral and cognitive interventions on the reduction of injection-associated pain in adults.

\section{Acknowledgments}

Lisa M Klumpp Callan, Robert Schupp, and Mary Hines of inScience Communications, Springer Healthcare, provided medical writing support funded by Bristol-Myers Squibb and AstraZeneca. Authors would like to thank Hiep Nguyen of AstraZeneca for his review of the manuscript.

\section{Disclosure}

The development of this manuscript was supported by Bristol-Myers Squibb and AstraZeneca.

Davida F Kruger has served on advisory boards for Novo Nordisk, Abbott Laboratories, Eli Lilly and Company, Sanofi-Aventis, Janssen Pharmaceuticals, Boehringer Ingelheim, DexCom, and Halozyme, has participated in speakers' bureaus for Janssen Pharmaceuticals, Valeritas, and Bristol-Myers Squibb/AstraZeneca, and has received research/grant support from Bristol-Myers Squibb/ AstraZeneca, Eli Lilly and Company, Halozyme, Novo Nordisk, and the Hemsley Foundation. A portion of her salary and benefits are provided by the National Institutes of Health. Phil Estepa was an employee of AstraZeneca at the time the work was completed. Susan LaRue was an employee of AstraZeneca at the time the work was completed and a former employee of Amylin Pharmaceuticals.

The authors report no other conflicts of interest in this work.

\section{References}

1. Defronzo RA. Banting Lecture. From the triumvirate to the ominous octet: a new paradigm for the treatment of type 2 diabetes mellitus. Diabetes. 2009;58(4):773-795.

2. Stratton IM, Adler AI, Neil HA, et al. Association of glycaemia with macrovascular and microvascular complications of type 2 diabetes (UKPDS 35): prospective observational study. BMJ. 2000;321(7258): 405-412.
3. American Diabetes Association. Standards of medical care in diabetes - 2013. Diabetes Care. 2013;36 Suppl 1:S11-S66.

4. Garber AJ, Abrahamson MJ, Barzilay JI, et al. American Association of Clinical Endocrinologists' comprehensive diabetes management algorithm 2013 consensus statement - executive summary. Endocr Pract. 2013;19(3):536-557.

5. Inzucchi SE, Bergenstal RM, Buse JB, et al; American Diabetes Association (ADA); European Association for the Study of Diabetes (EASD). Management of hyperglycemia in type 2 diabetes: a patientcentered approach: position statement of the American Diabetes Association (ADA) and the European Association for the Study of Diabetes (EASD). Diabetes Care. 2012;35(6):1364-1379.

6. Cook MN, Girman CJ, Stein PP, Alexander CM. Initial monotherapy with either metformin or sulphonylureas often fails to achieve or maintain current glycaemic goals in patients with type 2 diabetes in UK primary care. Diabet Med. 2007;24(4):350-358.

7. Cooke CE, Lee HY, Tong YP, Haines ST. Persistence with injectable antidiabetic agents in members with type 2 diabetes in a commercial managed care organization. Curr Med Res Opin. 2010;26(1):231-238.

8. Rubin RR, Peyrot M, Kruger DF, Travis LB. Barriers to insulin injection therapy: patient and health care provider perspectives. Diabetes Educ. 2009;35(6):1014-1022.

9. Nakar S, Yitzhaki G, Rosenberg R, Vinker S. Transition to insulin in type 2 diabetes: family physicians' misconception of patients' fears contributes to existing barriers. J Diabetes Complications. 2007;21(4): 220-226.

10. Peyrot M, Rubin RR, Lauritzen T, et al; International DAWN Advisory Panel. Resistance to insulin therapy among patients and providers: results of the cross-national Diabetes Attitudes, Wishes, and Needs (DAWN) study. Diabetes Care. 2005;28(11):2673-2679.

11. Polonsky WH, Fisher L, Guzman S, Villa-Caballero L, Edelman SV. Psychological insulin resistance in patients with type 2 diabetes: the scope of the problem. Diabetes Care. 2005;28(10):2543-2545.

12. Ratanawongsa N, Crosson JC, Schillinger D, Karter AJ, Saha CK, Marrero DG. Getting under the skin of clinical inertia in insulin initiation: the Translating Research Into Action for Diabetes (TRIAD) Insulin Starts Project. Diabetes Educ. 2012;38(1):94-100.

13. Tan AM, Muthusamy L, Ng CC, Phoon KY, Ow JH, Tan NC. Initiation of insulin for type 2 diabetes mellitus patients: what are the issues? A qualitative study. Singapore Med J. 2011;52(11):801-809.

14. Peyrot M, Rubin RR, Lauritzen T, Snoek FJ, Matthews DR, Skovlund SE. Psychosocial problems and barriers to improved diabetes management: results of the Cross-National Diabetes Attitudes, Wishes and Needs (DAWN) Study. Diabet Med. 2005;22(10):1379-1385.

15. Holt RI, Nicolucci A, Kovacs Burns K, et al; DAWN2 Study Group. Diabetes Attitudes, Wishes and Needs second study (DAWN2TM): cross-national comparisons on barriers and resources for optimal care healthcare professional perspective. Diabet Med. 2013;30(7):789-798.

16. Funnell MM. Overcoming barriers to the initiation of insulin therapy. Clin Diabetes. 2007;25(1):36-38.

17. Ali S, Stone MA, Peters JL, Davies MJ, Khunti K. The prevalence of co-morbid depression in adults with type 2 diabetes: a systematic review and meta-analysis. Diabet Med. 2006;23(11):1165-1173.

18. Anderson RJ, Freedland KE, Clouse RE, Lustman PJ. The prevalence of comorbid depression in adults with diabetes: a meta-analysis. Diabetes Care. 2001;24(6):1069-1078.

19. Gonzalez JS, Peyrot M, McCarl LA, et al. Depression and diabetes treatment nonadherence: a meta-analysis. Diabetes Care. 2008;31(12): 2398-2403.

20. Lustman PJ, Anderson RJ, Freedland KE, de Groot M, Carney RM, Clouse RE. Depression and poor glycemic control: a meta-analytic review of the literature. Diabetes Care. 2000;23(7):934-942.

21. Makine C, Karşidağ C, Kadioğlu P, et al. Symptoms of depression and diabetes-specific emotional distress are associated with a negative appraisal of insulin therapy in insulin-naïve patients with type 2 diabetes mellitus. A study from the European Depression in Diabetes [EDID] Research Consortium. Diabet Med. 2009;26(1):28-33. 
22. Karter AJ, Subramanian U, Saha C, et al. Barriers to insulin initiation: the translating research into action for diabetes insulin starts project. Diabetes Care. 2010;33(4):733-735.

23. Feitosa AC, Sampaio LN, Batista AG, Pinheiro CB. Frequency of fear of needles and impact of a multidisciplinary educational approach towards pregnant women with diabetes. Rev Bras Ginecol Obstet. 2013;35(3): 111-116.

24. Fu AZ, Qiu Y, Radican L. Impact of fear of insulin or fear of injection on treatment outcomes of patients with diabetes. Curr Med Res Opin. 2009;25(6):1413-1420.

25. Gill HS, Prausnitz MR. Does needle size matter? J Diabetes Sci Technol. 2007;1(5):725-729.

26. Ignaut DA, Fu H. Comparison of insulin diluent leakage postinjection using two different needle lengths and injection volumes in obese patients with type 1 or type 2 diabetes mellitus. J Diabetes Sci Technol. 2012;6(2):389-393.

27. Kreugel G, Keers JC, Kerstens MN, Wolffenbuttel BH. Randomized trial on the influence of the length of two insulin pen needles on glycemic control and patient preference in obese patients with diabetes. Diabetes Technol Ther. 2011;13(7):737-741.

28. Arendt-Nielsen L, Egekvist H, Bjerring P. Pain following controlled cutaneous insertion of needles with different diameters. Somatosens Mot Res. 2006;23(1-2):37-43.

29. Schwartz S, Hassman D, Shelmet J, et al. A multicenter, open-label, randomized, two-period crossover trial comparing glycemic control, satisfaction, and preference achieved with a 31 gauge $\times 6 \mathrm{~mm}$ needle versus a 29 gauge $\times 12.7 \mathrm{~mm}$ needle in obese patients with diabetes mellitus. Clin Ther. 2004;26(10):1663-1678.

30. Coghill RC, Gracely RH. Validation of combined numerical-analog descriptor scales for rating pain intensity and pain unpleasantness. 15th Scientific Meeting of the American Pain Society; November 14-17, 1996; Washington, DC.

31. Siegmund T, Blankenfeld H, Schumm-Draeger PM. Comparison of usability and patient preference for insulin pen needles produced with different production techniques: "thin-wall" needles compared to "regular-wall" needles: an open-label study. Diabetes Technol Ther. 2009;11(8):523-528.

32. Nagai Y, Ohshige T, Arai K, et al. Comparison between shorter straight and thinner microtapered insulin injection needles. Diabetes Technol Ther. 2013;15(7):550-555.

33. Chantelau E, Lee DM, Hemmann DM, Zipfel U, Echterhoff S. What makes insulin injections painful? BMJ. 1991;303(6793):26-27.

34. Hirsch L, Gibney M, Berube J, Manocchio J. Impact of a modified needle tip geometry on penetration force as well as acceptability, preference, and perceived pain in subjects with diabetes. J Diabetes Sci Technol. 2012;6(2):328-335.

35. Mollema ED, Snoek FJ, Heine RJ, van der Ploeg HM. Phobia of self-injecting and self-testing in insulin-treated diabetes patients: opportunities for screening. Diabet Med. 2001;18(8):671-674.

36. Funnell MM, Kruger DF, Spencer M. Self-management support for insulin therapy in type 2 diabetes. Diabetes Educ. 2004;30(2):274-280.
37. Welch G, Zagarins SE, Feinberg RG, Garb JL. Motivational interviewing delivered by diabetes educators: does it improve blood glucose control among poorly controlled type 2 diabetes patients? Diabetes Res Clin Pract. 2011;91(1):54-60.

38. Iwanaga M, Kamoi K. Patient perceptions of injection pain and anxiety: a comparison of NovoFine 32-gauge tip $6 \mathrm{~mm}$ and Micro Fine Plus 31-gauge 5mm needles. Diabetes Technol Ther. 2009;11(2):81-86.

39. Phillips P. Type 2 diabetes - failure, blame and guilt in the adoption of insulin therapy. Rev Diabet Stud. 2005;2(1):35-39.

40. Siminerio L, Kulkarni K, Meece J, et al. Strategies for Insulin Injection Therapy in Diabetes Self-Management. Chicago, IL: American Association of Diabetes Education; 2011. Available from: http:// www.diabeteseducator.org/export/sites/aade/_resources/pdf/research/ aade_meded.pdf. Accessed July 14, 2014

41. American Diabetes Association. Insulin administration. Diabetes Care. 2004;27 Suppl 1:S106-S109.

42. Hofman PL, Derraik JG, Pinto TE, et al. Defining the ideal injection techniques when using 5-mm needles in children and adults. Diabetes Care. 2010;33(9):1940-1944.

43. Rzeszut JR. Children with diabetes: the impact of fear of needles. J Pediatr Nurs. 2011;26(6):589-592.

44. Sparks L. Taking the "ouch" out of injections for children. Using distraction to decrease pain. MCN Am J Matern Child Nurs. 2001;26(2): $72-78$.

45. Uman LS, Chambers CT, McGrath PJ, Kisely S. A systematic review of randomized controlled trials examining psychological interventions for needle-related procedural pain and distress in children and adolescents: an abbreviated Cochrane review. J Pediatr Psychol. 2008;33(8): $842-854$.

46. Hauber AB, Johnson FR, Sauriol L, Lescrauwaet B. Risking health to avoid injections: preferences of Canadians with type 2 diabetes. Diabetes Care. 2005;28(9):2243-2245.

47. Hauber AB, Han S, Yang JC, et al. Effect of pill burden on dosing preferences, willingness to pay, and likely adherence among patients with type 2 diabetes. Patient Prefer Adherence. 2013;7:937-949.

48. Bae JP, Dobesh PP, Klepser DG, et al. Adherence and dosing frequency of common medications for cardiovascular patients. Am J Manag Care. 2012;18(3):139-146.

49. García-Pérez LE, Alvarez M, Dilla T, Gil-Guillén V, Orozco-Beltrán D. Adherence to therapies in patients with type 2 diabetes. Diabetes Ther. 2013;4(2):175-194.

50. Srivastava K, Arora A, Kataria A, Cappelleri JC, Sadosky A, Peterson AM. Impact of reducing dosing frequency on adherence to oral therapies: a literature review and meta-analysis. Patient Prefer Adherence. 2013;7:419-434.

51. Hauber AB, Nguyen H, Posner J, Ervin C, LaRue S, Kalsekar I. Patient preferences for frequency of glucagon-like peptide-1 receptor agonist (GLP-1RA) injections in the treatment of type 2 diabetes. International Society for Pharmacoeconomics and Outcomes Research (ISPOR) 19th Annual International Meeting; 2014 May 31-June 4; Montreal, QC, Canada. Value Health. 2014;17(3):A255.

\section{Publish your work in this journal}

Diabetes, Metabolic Syndrome and Obesity: Targets and Therapy is an international, peer-reviewed open-access journal committed to the rapid publication of the latest laboratory and clinical findings in the fields of diabetes, metabolic syndrome and obesity research. Original research, review, case reports, hypothesis formation, expert opinion and commentaries are all considered for publication. The manuscript management system is completely online and includes a very quick and fair peer-review system, which is all easy to use. Visit http://www.dovepress.com/testimonials.php to read real quotes from published authors. 